\title{
Maternal positioning affects fetal heart rate changes after epidural analgesia for labour
}

Roanne Preston MD, ${ }^{*}$ Edward T. Crosby MD, ${ }^{*}$

D. Kotarba MD, $\dagger$ Helene Dudas RN, $\ddagger$

Robert D. Elliott $M D^{*}$

Adverse fetal heart rate (FHR) changes suggestive of fetal hypoxia are seen in patients with normal term pregnancies after initiation of epidural block for labour analgesia. It was our hypothesis that, in some parturients, these changes were a consequence of concealed aortocaval compression resulting in decreased uterine blood flow. We expected that the full lateral position compared with the wedged supine position would provide more effective prophylaxis against aortocaval compression. To test our hypothesis we studied the role of maternal positioning on FHR changes during onset of epidural analgesia for labour. Eighty-eight ASA Class I or II term parturients were randomized into two groups: those to be nursed in the wedged supine position and those to be nursed in the full lateral position during induction of an epidural block. External FHR monitoring was employed to assess the fetal response to initiation of labour epidural analgesia. Epidural catheters were sited with the parturients in the sitting position and the patients then assumed the study position. After a negative test dose, a standardized regimen of bupivacaine $0.25 \%$ was employed to provide labour analgesia. The quality and efficacy of the block were assessed using VAS pain scores, motor block scores and sensory levels. The results demonstrated that there was no

Key words

ANAESTHESIA: obstetrical; ANAESTHETIC TECHNIQUES: regional, epidural.

From the Departments of Anaesthesia*, Obstetrics and Gynaecology† and Nursingt, Ottawa General Hospital, University of Ottawa, 501 Smyth Road, Ottawa, Ontario, K1H 8L6.

Presented, in part, in the Residents' Competition at the Canadian Anaesthetist's Society Annual Meeting, June 1992, Toronto, Ontario, Canada.

Address correspondence to: Dr. Edward T. Crosby, Department of Anaesthesia, Module A-11, Ottawa General Hospital, 501 Smyth Road, Ottawa, Ontario, Canada, K1H 8L6.

Accepted for publication 16th August, 1993. difference in the quality of analgesia provided nor in the incidence of asymmetric blocks. There was no difference in the observed incidence of FHR changes occurring during the initiation of the epidural block. However, six of 38 women (15\%) nursed in the wedged supine position had severe FHR decelerations compared with none in the patients nursed in the full lateral position $(P<0.05)$. We recommend the use of the full lateral position to nurse women in labour during the initiation of labour epidural analgesia.

Après linitiation de l'analgésie épidurale pour le travail, on constate souvent chez la parturiente à terme des variations inquiétantes de fréquence cardiaque foetale qui sont suggestifs d'hypoxie. Nous présumons que chez certaines parturientes, ces changements peuvent être causés par une compression aortocave latente. Si tel est le cas, le décubitus latéral strict pourrait mieux prévenir la compression aortocave que la position de décubitus dorsal avec surélévation latérale droite. Pour vérifier cette hypothèse, nous avons étudié les effets de la position de la mère pendant l'installation de l'analgésie épidurale pour le travail. Quatre vingt-huit parturientes ASA I et II à terme sont reparties au hasard entre deux groupes pendant linstallation de l'analgésie: décubitus dorsal avec surélévation latérale droite et décubitus latéral strict. Pour mesurer la réponse du foetus, on utilise un moniteur de fréquence cardiaque externe. Le cathéter épidural est inséré en position assise et, ensuite, on place la patiente dans la position désirée. Après une dose-test négative, l'analgésie est réalisée par l'administration d'une dose standard de bupivacaïne $0,25 \%$. La qualité et l'efficacité du bloc sont évaluées sur l'échelle analogue de la douleur, sur l'échelle de motricité et par le niveau sensitif atteint. Les résultats montrent qu'on n'a pas observé de différence au regard de la qualité de l'analgésie et de lincidence de blocs asymétriques. On n'a pas non plus démontré de différence pour la fréquence des variations de la fréquence cardiaque foetale pendant linstallation du bloc épidural. Cependant, six des 38 parturientes (15\%) maintenues en décubitus dorsal avec surélévation latérale droite ont présenté des décélérations foetales importantes comparativement à aucune pour celles qui ont été maintenues en décubitus latéral $(P<0,05)$. Nous recommandons que la parturiente en travail soit maintenue en décubitus latéral pendant linitiation de l'analgésie épidurale. 
Fetal heart rate (FHR) changes are seen in $16-27 \%$ of parturients during the initiation of an epidural block for labour analgesia. ${ }^{1-3}$ Decelerations are more commonly registered from fetuses of parturients who become hypotensive during the initiation of the block but they also occur when no maternal hypotension is recorded. ${ }^{4}$ Late or variable decelerations that are moderate to severe or prolonged occur in $8.5-8.9 \%$ of parturients. ${ }^{2,5}$ This incidence may increase to $19 \%$ if bupivacaine $0.5 \%$ is used to initiate the block. ${ }^{2}$ These FHR changes have been attributed to fetal uptake of local anaesthetic. ${ }^{2}$ However, a return to a normal FHR pattern is often accelerated in non-hypotensive patients by placing the mother in the full lateral position suggesting that these FHR changes may be related to decreases in uterine perfusion. ${ }^{4}$ In the absence of maternal hypotension, it is possible that uterine hypoperfusion results from incomplete but important aortocaval compression. In support of this hypothesis, Boehm has reported that $53 \%$ of fetuses demonstrated decreased baseline variability during initiation of epidural analgesia when the mothers are nursed in the supine position even though maternal hypotension may not have been present. ${ }^{1}$ Aortocaval compression resulting in supine hypotension syndrome is seen in up to $15 \%$ of pregnant women near term. ${ }^{6}$ Maternal symptoms of shock, including hypotension, pallor, diaphoresis, nausea and vomiting, occur as do fetal heart pattern changes suggestive of asphyxia (bradycardia, decelerations, and decreased variability). This syndrome occurs because of severe compression of the aortocaval system by the gravid uterus. Clinical improvement in both the fetal and maternal condition is usually seen with repositioning the mother into the lateral position, thereby relieving the compression and improving both venous return to the heart and arterial flow to the uterus. Lesser degrees of aortocaval compression may be clinically silent until they are unmasked or potentiated by factors associated with labour and labour analgesia. Sympathetic blockade associated with epidural analgesia may exacerbate the importance of lesser degrees of aortocaval compression by impairing the parturient's ability to compensate for minor decreases in blood pressure via peripheral vasoconstriction. ${ }^{7}$ As well, uterine hypertonicity or contractions may further diminish uterine blood flow and may trigger evidence of fetal distress as placental reserve exceeds its level of tolerance.

It was our hypothesis that the wedged supine position traditionally used to nurse women in labour fails to prevent aortocaval compression adequately in all parturients, thus compromising uterine blood flow and fetal oxygen supply. Fetal heart rate changes may result and be incorrectly attributed to the epidural block. We predicted that the full lateral position would provide better prophylaxis than the wedged supine position against aor- tocaval compression during onset of an epidural block, and would result in a reduced incidence of abnormal FHR patterns subsequent to initiation of epidural block. Finally, it was our hypothesis that the full lateral position would not result in a diminished efficacy of the epidural block.

\section{Methods}

This prospective, randomized study was approved by the hospital Ethics Committee. Criteria for inclusion were: ASA Class I or II; uncomplicated term, singleton pregnancy; spontaneous onset and non-augmented labour; vertex presentation; and a normal fetal heart pattern. All eligible patients entering the case room received an information sheet about the study. If they requested epidural analgesia, they were asked to participate in the study.

Informed consent was obtained and the patients were randomized into two groups: those to be nursed in the wedged supine position (Group I) and; those to be nursed in the full lateral position (Group II) during initiation of an epidural block for labour analgesia. Before insertion of the epidural catheter, the patients received one litre of Ringer's lactate $\dot{i}$. With the patient in the sitting position, an epidural catheter was sited at the $\mathrm{L}_{2-3}$ or $\mathrm{L}_{3-4}$ interspace by the attending anaesthetist or anaesthesia resident. The patients were then positioned according to group assignment, with a $30^{\circ}$ wedge cushion (Posey foam wedge, $\odot$ J.T. Posey Co., 5635 Peck Road, Arcadia, Calif) used in the wedge supine group to standardize positioning. A test dose (TD) of $3 \mathrm{ml}$ lidocaine $1.5 \%$ with 15 $\mu \mathrm{g}$ adrenaline was then administered. After five minutes, with no evidence of misplaced injection, $4 \mathrm{ml}$ bupivacaine $0.25 \%\left(I_{1}\right)$ was injected through the catheter, followed in five minutes by a further $3 \mathrm{ml}$ of the same solution $\left(I_{2}\right)$. A continuous infusion of $0.25 \%$ bupivacaine was then started at $7-8 \mathrm{ml} \cdot \mathrm{hr}^{-1}$

Before the epidural catheter was inserted, an external fetal heart monitor was placed, a normal FHR trace was confirmed and a five-minute control strip was taken. After the catheter was sited, the monitor was reactivated and the test dose given. The times of the injection were marked on the strip as TD, $I_{1}$ and $I_{2}$. The fetal heart strip was marked at five-minute intervals after the injection of the second dose of bupivacaine $\left(I_{2}\right)$ as $I_{2} 5, I_{2} 10, I_{2} 15, I_{2}$ $20, I_{2} 25$, and $I_{2} 30$. The continuous trace could then be divided into eight epochs. The FHR patterns during each were analyzed. The study was terminated after 30 min. The FHR strips were reviewed by an obstetrician blinded to the study groups and to the nature of the interventions (TD, $I_{1}, I_{2}, I_{2} x$ ). The incidence of FHR changes was noted in each group. Each epoch was evaluated and if an abnormality was recorded in the epoch 
it was denoted as an event. The event count was a measure of the duration of abnormal FHR traces in the two groups. The time at which the changes occurred within the study period was noted and the changes were further categorized as severe if there was FHR less than 100 $\mathrm{bpm}$ or decelerations of $60 \mathrm{bpm}$ below control values or lasting more than 60 seconds or both.

Maternal blood pressure was recorded before siting the epidural catheter and then every five minutes for the duration of the study. A decrease in maternal blood pressure of greater than $30 \%$ from control or $<100 \mathrm{mmHg}$ was treated with incremental boluses of ephedrine $(5-7.5 \mathrm{mg})$ $i v$.

Pain relief was assessed with a visual analogue score (VAS), utilizing a scale from 0 to 10 , at the following times: before insertion of the epidural catheter, and at 10,20 , and $30 \mathrm{~min}$ after completion of the $\mathrm{I}_{2}$ injection. Motor block on a scale of 0 to 3 was assessed at the 30-min interval and the sensory level was approximated using temperature discrimination to an alcohol swab.

At the 20-min interval, parturients were assessed for the presence of a unilateral block and repositioned if necessary on the opposite (right) side. If the parturient was still uncomfortable at $30 \mathrm{~min}$ she was given a further $5 \mathrm{ml}$ plain bupivacaine $0.25 \%$. A failed block resulted in the patient being removed from the study and a second catheter was inserted by the attending anaesthetist.

The data obtained were analyzed using Chi-squared and Fisher's exact test for differences between the two groups in motor block, sensory level, unilateral blocks, visual analogue pain scores, and FHR changes. A onetailed test of significance was used to assess FHR changes and a two-tailed test was used for all other outcomes. A one-tailed test was considered appropriate as it was our hypothesis that the incidence of FHR changes would be higher in the wedged supine group. A $P<0.05$ was considered to be statistically significant.

\section{Results}

Eight-eight patients were enrolled in the study, but 15 were excluded from the data analysis ( 8 Group 1, 7 Group II) because of failed block (6), incomplete data (8), or failure to follow to protocol (1). Thirty-eight patients remained in Group I and 35 in Group II. There were no differences between the two groups as far as height or weight, and all participants had normal term pregnancies.

\section{Epidural block characteristics}

The peak sensory level according to dermatome was no different between the two groups, most women having $T_{9}$ to $T_{10}$ blocks. One woman in the Group I developed a $T_{1}$ block, and in the Group II one parturient had a $\mathrm{T}_{4}$ block. The number of uneven blocks at $20 \mathrm{~min}$, de-
TABLE I Characteristics of the epidural block

\begin{tabular}{llll}
\hline Characteristic & $\begin{array}{l}\text { Wedged supine } \\
\text { position }\end{array}$ & $\begin{array}{l}\text { Full lateral } \\
\text { position }\end{array}$ & $P$ \\
\hline Number of patients & 38 & 35 & \\
Initial VAS score & & & \\
$-4-7$ & 18 & 15 & NS \\
-8 -10 & 20 & 20 & NS \\
Motor block & & & \\
- None & 24 & 25 & NS \\
- Partial & 13 & 10 & NS \\
- Full & 1 & 0 & NS \\
Uneven block & 2 & 5 & NS \\
Repositioned at 20 min & 13 & 13 & NS \\
Unilateral block at 30 min & 1 & 0 & NS \\
Local anaesthetic supplement & & & \\
$\quad$ at 30 min & 2 & 3 & NS \\
Final VAS score & & & \\
- 0-3 & 35 & 31 & NS \\
- 4-7 & 3 & 3 & NS \\
\hline
\end{tabular}

TABLE II Analysis of the FHR strips

\begin{tabular}{llll}
\hline FHR characteristic & $\begin{array}{l}\text { Wedged supine } \\
\text { position }\end{array}$ & $\begin{array}{l}\text { Full lateral } \\
\text { position }\end{array}$ & $P$ \\
\hline FHR strips evaluated & 38 & 35 & \\
Events recorded & 33 & 18 & NS \\
FHR changes & 13 & 7 & NS \\
Decreased variability & 2 & 0 & NS \\
Decelerations & 10 & 6 & NS \\
Tachycardia & 3 & 1 & NS \\
Severe changes* & 6 & 0 & $<0.05$ \\
\hline
\end{tabular}

*FHR $<100 \mathrm{bpm}$, Deceleration $>60 \mathrm{bpm}$ for $>60 \mathrm{sec}$.

fined as a greater than three dermatome difference between sides, was two in Group I and five in Group II (NS). An equal number of women (13 per group), required repositioning at the 20 min mark. Supplementation of the block at $30 \mathrm{~min}$ because of persistent discomfort was required in the same number of patients in each group (two in Group I, three in Group II). The majority of patients in both groups had either no or a partial motor block (grade 0 or 1). Pain relief as assessed by the VAS was not different between the two study groups either at the beginning of the study or at the end of the study period (Table I).

\section{Fetal heart pattern changes}

There was no difference in the number of women having FHR changes during the study period (13 in Group I, 7 in Group II) (Table II). The most frequent changes detected were decelerations, again with no difference between the two groups. Although there were twice as many events observed in Group I, the difference was not statistically significant (Table II). The majority of the events 
occurred 10 to $25 \mathrm{~min}$ after the full analgesic dose of bupivacaine had been injected. The FHR changes considered severe by protocol criteria occurred more frequently in Group I than in Group II (15\% vs $0 \%)(P$ $<0.05$ ). The severe decelerations in these six women did not coincide with any episode of maternal hypotension (systolic blood pressure decrease $>30 \%$ of the control value or blood pressure below 100 systolic), and all these women were in the wedged supine position when the decelerations started. Three women were repositioned on to their right sides when the decelerations persisted. Of the six women in Group I whose fetuses had severe decelerations, three had persistent FHR abnormalities. One patient went to urgent Caesarean section, the Apgar score was 3 at one minute and 8 at five minutes. The other two were delivered by vacuum extraction. Both babies had normal Apgar scores. There were no adverse feto-maternal outcomes amongst the pairs with FHR changes nor in any other study participants.

\section{Discussion}

This study demonstrated that, when compared with the use of the wedged supine position, use of the full lateral position decreased the incidence of severe FHR changes seen in some women with onset of epidural analgesia. We attribute this result to the more effective prevention of aortocaval compression by the full lateral position. Although the incidence of all FHR changes was numerically greater in the patients nursed in the wedged supine position, the difference was not significant. This could have been due to an inadequate number of patients being studied to detect a difference. If the incidence is similar to that detected in our study, a power analysis suggests that 62 patients in each group would have to have been studied for the results to have reached significance.

The wedged supine position is used in many obstetrical centres to nurse women in labour in order to prevent aortocaval compression and its detrimental effects on maternal cardiac output and hence uterine blood flow. However, shortly after onset of epidural analgesia for labour, adverse FHR changes are demonstrated in a significant proportion of patients. ${ }^{1-5}$ These changes are more commonly observed in patients who become hypotensive as a result of the epidural block, in those who are undergoing oxytocin augmentation of labour or where evidence of uterine hypertonicity is present and in those patients with pregnancies complicated by maternal disease. ${ }^{4,5,8-11}$ In our study, the FHR decelerations observed were not associated with maternal hypotension.

In the normal parturient, FHR changes occurring concurrent with the initiation of epidural analgesia were often considered to be secondary to fetal uptake of local anaesthetic. Bupivacaine, in particular, was identified as an agent with a higher than average association with heart pattern changes. ${ }^{2}$ However, the FHR changes observed, including late decelerations, fetal bradycardia and transient decreases in baseline variability are also indicators of acute fetal hypoxia. As such, they could reflect marked decreases in uterine blood flow and placental insufficiency occurring at the time of onset of epidural analgesia even in the parturient without risk factors for compromised placental circulation. The placental insufficiency and fetal hypoxia could result from the summating effect of a number of concurrently occurring events in a healthy pregnancy that individually would normally have little impact on the well-being of the fetus. For example, should a contraction occur and result in decreased uterine blood flow at a time when the parturient's positioning had already resulted in partial aortocaval obstruction thus decreasing uterine perfusion, the onset of an epidural blockinduced sympatholysis would limit the parturient's ability to compensate for the aortocaval compression. The net effect could be a critical decrease in placental perfusion manifested by a fetal heart trace evidence of hypoxia. If the frequency of contractions does not allow for fetal recovery, then subsequent contractions will trigger a more severe response because of the already disturbed homeostasis. Steiger has reported an $8.5 \%$ incidence of prolonged decelerations with initiation of epidural block and a higher incidence of uterine hypertonus in those patients experiencing decelerations compared with those patients who did not. ${ }^{5}$ Provided that the effect of one or more of the above factors was self-limited or resolved with a medical-nursing intervention, then the evidence of fetal compromise would be transient and a good outcome would be anticipated. However, it is possible that the situation could deteriorate to the extent that an urgent Caesarean section is required to ensure an acceptable outcome. Appropriate recognition of such a potential, neither common nor rare, and aggressive positional prophylaxis against concealed aortocaval compression may reduce the likelihood of such a scenario.

The incidence of ominous FHR changes in our study is high. We do not have data to calculate our incidence of FHR changes following initiation of epidural block outside of our study population and suspect that few centres do. However, our overall incidence of severe changes $(6 / 73=8.2 \%)$ is consisted with the $8.5 \%$ estimated incidence of persistent decelerations during initiation of epidural block in labour reported by Steiger and is considerably less than the $19 \%$ incidence of moderate to severe or prolonged decelerations reported by Abboud when bupivacaine $0.5 \%$ was used to initiate labour epidural block. ${ }^{2,5}$ The power of the zero numerator $(0 / 35$ patients with severe decelerations) in the full lateral group cannot be discounted in analysing our results. With this 
finding, we can be confident only that the true incidence of severe FHR changes with the use of the full lateral position will not be much greater than $8.6 \% .{ }^{12}$ As well, the possibility of a sampling error leading to a type I error in a study sample of this size must be considered.

Our use of a one-tailed test for the analysis of the FHR changes is supported by our initial hypothesis that the full lateral position would be better able to prevent FHR changes than the wedged supine position. This trial was designed to confirm a clinical impression and we were consistent in stating both our hypothesis and our intent to use a one-tailed test at the outset of the trial. [The reader must be aware that the cut-off value for calling a test statistic big is smaller for any given $P$ value when using a one-tailed test.] Again, the possibility of a type I error must be considered.

External FHR monitoring was used for the study because it is the current standard of care in our institution for normal parturients at term and because it is noninvasive. This form of monitoring is not as sensitive a tool to assess changes in fetal heart variability as is an internal monitor; however, this bias would affect both study groups equally. The only FHR change that was significantly different in this study was that of severe fetal heart decelerations, which are readily detected with external fetal heart monitoring.

Overall, there was no difference in satisfaction with the epidural analgesia obtained by the women in the two groups. The efficacy of the epidural block in providing adequate labour analgesia was not adversely affected by use of the full lateral position. During the study period, one-third of the women in each of the groups were repositioned for reasons of discomfort or uneven blocks. Although there was no difference in the incidence of unilateral blocks between the groups, there were numerically more patients with uneven blocks among those nursed in the full lateral position. It is possible, had a larger number of patients been studied, that this difference would have reached statistical significance. If we assume that our incidence of uneven blocks across the study population $(7 / 73=9.5 \%)$ is true, then we would have to study over 400 parturients to be confident that uneven blocks were not twice as common in one group as compared with the other. It is recognized that it is only when the blocks are so asymmetric as to impair analgesia that this achieves clinical importance. However, this issue must be resolved as it will continue to discourage anaesthetists from routinely using the full lateral position. Maintaining the patient in the lateral position during the initiation of epidural labour analgesia has been previously reported to be compatible with satisfactory analgesia for labour. ${ }^{13}$ Asymmetric blocks, defined as a two or more dermatome difference, can and do occur when the lateral position is maintained during epidural analgesia and Merry reported an incidence of $30 \%$ when $8 \mathrm{ml}$ bupivacaine $0.5 \%$ were employed to initiate the block. ${ }^{14}$ The incidence was similar to that seen in our study but there was no difference in the group maintained in the wedge supine position. With the use of larger volume injections to provide anaesthesia for Caesarean section lateralization is often seen during the development of the block but there is no difference in dermatomal levels when the block is fully developed. ${ }^{15,16}$

We have demonstrated a decrease in ominous fetal heart pattern changes when normal term parturients are nursed in the full lateral position compared to the conventional wedged supine position during initiation of epidural block for labour analgesia. It is our opinion that this is due to concealed aortocaval compression that is not prevented in all patients by the wedged supine position but that is more effectively prevented by the full lateral position. We recommend that, in order to reduce the incidence of adverse FHR changes which are seen frequently when epidural analgesia is initiated, the full lateral position be the preferential position for nursing women. In parturients at high risk for placental insufficiency, the full lateral position should be employed as a routine to nurse the patient at least during the initial development of the epidural block. The fetus should be continuously monitored for not less than $30 \mathrm{~min}$ after initiation of an epidural block for labour.

\section{References}

1 Boehm FH, Woodruff LF, Growdon JH. The effect of lumbar epidural anesthesia on fetal heart rate baseline variability. Anesth Analg 1975; 54: 779-82.

2 Abboud TK, Khoo SS, Miller F, Doan T, Henriksen EH. Matemal, fetal, and neonatal responses after epidural anaesthesia with bupivacaine, 2-chloroprocaine, or lidocaine. Anesth Analg 1982; 61: 638-44.

3 Abboud TK, Afrasiabi A, Sarkis F, et al. Continuous infusion epidural analgesia in parturients receiving bupivacaine, chloroprocaine, or lidocaine - maternal, fetal, and neonatal effects. Anesth Analg 1984; 63: 421-8.

4 Schifrin BS. Fetal heart rate patterns following epidural anaesthesia and oxytocin infusion during labour. Journal of Obstetrics and Gynaecology of the British Commonwealth 1972; 79: 332-9.

5 Steiger RM, Nageotte MP. Effect of uterine contractility and maternal hypotension on prolonged decelerations after bupivacaine epidural anaesthesia. Am J Obstet Gynecol 1990; 163: 808-12.

6 Cheek TG, Gutsche BB. Maternal physiologic alterations during pregnancy. In: Shnider SM, Levinson G (Eds.). Anesthesia for Obstetrics, 2nd ed. Baltimore: Williams \& Wilkins, 1987; 3-13. 
7 Wright RG, Shnider SM. Hypotension and regional anaesthesia in obstetrics. In: Shnider SM, Levinson G (Eds.). Anesthesia for Obstetrics, 2nd ed, Baltimore: Williams \& Wilkins, 1987; 293-9.

8 Lavin JP. The effects of epidural anesthesia on electronic fetal heart rate monitoring. Clin Perinatol 1982; 9: 55-62.

9 Lavin JP, Samuels SV, Miodovnik M, Holroyde J, Loon $M$, Joyce $T$. The effects of bupivacaine and chloroprocaine as local anesthetics for epidural anesthesia on fetal heart rate monitoring parameters. Am J Obstet Gynecol 1981; 141: 717-22.

10 Cibils $L A$. Clinical significance of fetal heart rate patterns during labor. II. Late decelerations. Am J Obstet Gynecol 1975; 123: 473-94.

11 Rickford WJK, Reynolds $F$. Epidural analgesia in labour and maternal posture. Anaesthesia 1983; 38: 1169-74.

12 Hanley $J A$, Lippman-Hand A. If nothing goes wrong, is everything all right? Interpreting zero numerators. JAMA 1983; 249: 1743-5.

13 Rolbin SH, Cole AFD, Hew EM, Virgint S. Effect of lateral position and volume on the spread of epidural anaesthesia in the parturient. Can Anaesth Soc J 1981; 28: 431-5.

14 Merry AF, Cross JA, Mayadeo SV, Wild CJ. Posture and the spread of extradural analgesia in labour. $\mathrm{Br} \mathrm{J}$ Anaesth 1983; 55: 303-7.

15 Pitkanen MT, Paatero H, Rosenberg PH. The effect of maternal lateral position or position change on epidural anesthesia and plasma bupivacaine concentrations. Reg Anesth 1988; 13: 157-61.

16 Norris $M C$, Leighton BL, DeSimone CA, Larijani GE. Lateral position and epidural anaesthesia for cesarean section. Anesth Analg 1988; 67: 788-90. 